\title{
Influence of Silicone Oil Tamponade after Vitrectomy on Intraocular Pressure
}

\author{
AMANY A.M. TAWFIK, M.Sc.; NEGMELDIN H. ABDALLAH, M.D.; LAMIA S. ELEWA, M.D. and \\ NOURELDIN HUSSEIN, M.D.
}

The Department of Ophthalmology, Faculty of Medicine, Ain Shams University

\begin{abstract}
Background: Glaucoma is a complicated disease in which damage to the optic nerve leads to progressive, irreversible vision loss. Glaucoma is the second leading cause of blindness.

Aim of Study: The aim of this study is to determine the possible influence of the silicone oil tamponade after vitrectomy on the intraocular pressure which is a major risk factor for developing secondary glaucoma and the effect of starting with anti-glaucoma therapy during the first 6 months postoperative.
\end{abstract}

Patients and Methods: This prospective study was conducted from February 2018 to August 2018 and involved 35 patients ( 25 patients with retinal detachment, 10 patients with advanced proliferative diabetic retinopathy). All patients had vitrectomy with silicone oil tamponade. All patients signed an informed consent to participate in the study.

Results: Early elevation of IOP is equally present in the patients with RD as well as in those with PDR. However, a qualitative analysis of the two groups of patients showed higher IOP in patients with PDR. Silicone oil significantly affect visual acuity in both groups of patients causing deterioration of the visual acuity which affect PDR group more than RD group.

Conclusion: Silicone oil as a tamponade agent after pars plana vitrectomy may cause rise in the IOP values in the early post-operative period in some patients. Therefore the timely detection and appropriate antiglaucoma treatment is extremely important since every elevation of the IOP may interfere with the positive outcome of the surgical procedure and functional visual outcome.

Key Words: Silicone oil tamponade - Vitrectomy - Intraocular pressure.

\section{Introduction}

GLAUCOMA is a complicated disease in which damage to the optic nerve leads to progressive, irreversible vision loss. Glaucoma is the second leading cause of blindness [1].

Correspondence to: Dr. Amany A.M. Tawfik, E-Mail: amanymohamed1836@yahoo.com
Risk factor for glaucoma include increased IOP greater than $21 \mathrm{mmHg}$, family history, high blood pressure and obesity [1]. However some may have high IOP for years and never develop damage [2] Conversely, optic nerve damage may occur with normal pressure, known as normal tension glaucoma [3].

There are several different types of glaucoma, including open angle glaucoma and acute angle closure glaucoma. The treatment of glaucoma may include medication, surgery or laser surgery [3]

Vitrectomy is an operation to remove the vitreous gel from the eye. Common indications include retinal detachment, vitreous hemorrhage, macular hole and intraocular foreign body [4]

Silicone oil is a synthetic polymer made of repetitive ( $\mathrm{Si}-\mathrm{O}$ units) and is chemically similar to silicone rubber, except that silicone oil polymer chains are not cross-linked and are shorter than those of silicone rubber [5]. Silicone oil was first introduced by Cibis in 1962 for vitreoretinal surgery [6].

Today silicone oil is an important adjunct for internal tamponade in a wide variety of vitreoretinal surgeries. Silicone oil instilled in the vitreous cavity ensures stability of the eye ball, restores the initial intraocular anatomical relations and slows down further proliferation, it is well tolerated and because of its transparency it enables easier post-operative visualization of the posterior segment $[7,8]$. Apart from the possible development of band keratopathy and Corneal decompensation one of the major side effects of the silicone oil is secondary IOP elevation $[9,10]$.

Secondary glaucoma can occur at any time in the post-operative period and may range from mild 
and transient to severe and sustained IOP spikes, resulting in loss of vision [11].

Mechanisms responsible for developing secondary glaucoma are pupillary block [12], emulsified silicone oil bubbles in the chamber angle [13], angle closure by anterior synechial, inflammation, rubeosis iridis and idiopathic IOP rise after silicone oil instillation. The majority of these cases are well controlled by topical anti-glaucoma therapy, whereas the minority of patients require evacuation of the silicone oil to normalize IOP and the most refractory cases mandate penetrating filtration surgery in order to stabilize the IOP in the long term [14]

\section{Aim of the work:}

The aim of this study is to determine the possible influence of the silicone oil tamponade after vitrectomy on the intraocular pressure which is a major risk factor for developing secondary glaucoma and the effect of starting with anti-glaucoma therapy during the first 6 months post-operative.

\section{Patients and Methods}

This prospective study was conducted at Ain Shams University Hospitals from February 2018 to February 2019 on patients who were operated for rhegmatogenous RD and proliferative diabetic retinopathy (vitreous hemmorrhage). All patients had vitrectomy 23 gauge with silicone oil (1000 cs) tamponade. All patients signed an informed consent to participate in the study.

\section{Study inclusion criteria:}

- Patients of age 30-70 years.

- Patients have PPV with SOI.

Study exclusion criteria:

- Age less than 30 and more than 70 years.

- Patients with corneal decompensation.

- Cataract.

- Uveitis.

- Significant complication of surgery.

- Previous history of glaucoma and RD surgery in the same eye.

\section{All patients underwent:}

- Medical history for having any chronic disease (e.g., Hypertension (HTN), Diabetes Mellitus (DM), etc.).

- Ocular history taking for any chronic eye condition, previous ocular surgery (e.g., glaucoma, vitrectomy. etc.), past history of eye trauma, retinal detachment, vitreous or retinal hemorrhage and positive family history of glaucoma or other eye disease.

All patients had complete ophthalmologic examination which included:

- Assessment of visual acuity using auto chart projector (ACP-8) (Made in Japan).

- Examination of anterior segment using slit lamp biomicroscopy TOPCON (SL-3C) (Made in Japan).

- IOP measurement with applanation tonometry HAAG-STREIT (AT 900®). Swiss made.

- Gonioscopy was performed.

- Posterior segment examination with indirect ophthalmoscope using 20D lenses and with slit lamp using VOLK non-contact +90 lens (Made in Japan).

- B scan done before surgery.

Statistical analysis:

Data were analyzed using Statistical Program for Social Science (SPSS) 12 statistical package. Probability ( $p$-value): $p$-value $<0.05$ was considered significant, $p$-value $<0.001$ was considered as highly significant, $p$-value $>0.05$ was considered insignificant.

\section{Results}

In our study 35 patients of age range from 32 to 67 years, 12 female and 23 male, there was right eye involvement in 17 cases and left eye involvement in 18 cases, 10 with PDR and 25 with RD, 23 were phakic and 12 were pseudophakic underwent pars plana vitrectomy (23 gauge) with silicone oil injection (1000cs).

The mean pre-operative IOP was $15.40 \mathrm{mmHg}$ with SD \pm 3.34 (range: 9 to $22 \mathrm{mmHg}$ ). The mean post-operative IOP in the first day after PPV was $18.20 \mathrm{mmHg}$ with SD \pm 3.40 (range: 10 to $24 \mathrm{~mm}$ $\mathrm{Hg}$ ). The mean post-operative IOP after one week of surgery was $18.63 \mathrm{mmHg}$ with SD \pm 4.60 (range: 9 to $27 \mathrm{mmHg}$ ). The mean post-operative IOP after two weeks of surgery was $20.69 \mathrm{mmHg}$ with SD \pm 8.94 (range: 8 to $49 \mathrm{mmHg}$ ). The mean postoperative IOP after one month of surgery was 17.36 $\mathrm{mmHg}$ with SD \pm 4.92 (range: 8 to $30 \mathrm{mmHg}$ ). The mean post-operative IOP after two months of surgery was $17.13 \mathrm{mmHg}$ with SD \pm 4.75 (range: 10 to $34 \mathrm{mmHg}$ ). The mean post-operative IOP after six months of surgery was $16.60 \mathrm{mmHg}$ with SD \pm 3.30 (range: 8 to $24 \mathrm{mmHg}$ ). 
Table (1): IOP pre and post-operative.

\begin{tabular}{|c|c|c|c|c|}
\hline IOP & No. $=35$ & $\begin{array}{c}\text { Mean } \pm \text { SD } \\
\text { or differences }\end{array}$ & $\begin{array}{l}t- \\
\text { test }\end{array}$ & $p$ \\
\hline \multicolumn{5}{|l|}{ Pre-operative: } \\
\hline Mean \pm SD & $15.40 \pm 3.34$ & - & - & - \\
\hline Range & $9-22$ & & & \\
\hline \multicolumn{5}{|l|}{ First day: } \\
\hline Mean \pm SD & $18.20 \pm 3.40$ & $2.80 \pm 3.20$ & 5.181 & 0.000 \\
\hline Range & $10-24$ & & & \\
\hline \multicolumn{5}{|l|}{ First week: } \\
\hline Mean \pm SD & $18.63 \pm 4.60$ & $3.23 \pm 4.65$ & 4.110 & 0.000 \\
\hline Range & $9-27$ & & & \\
\hline \multicolumn{5}{|l|}{ Second week: } \\
\hline Mean \pm SD & $20.69 \pm 8.94$ & $5.29 \pm 8.89$ & 3.516 & 0.001 \\
\hline Range & $8-49$ & & & \\
\hline \multicolumn{5}{|l|}{ First month: } \\
\hline Mean \pm SD & $17.36 \pm 4.92$ & $2.00 \pm 5.15$ & 2.229 & 0.033 \\
\hline Range & $8-30$ & & & \\
\hline \multicolumn{5}{|l|}{ Second month: } \\
\hline Mean \pm SD & $17.13 \pm 4.75$ & $1.97 \pm 4.87$ & 2.213 & 0.035 \\
\hline Range & $10-34$ & & & \\
\hline \multicolumn{5}{|l|}{ Six months: } \\
\hline Mean \pm SD & $16.60 \pm 3.30$ & $1.43 \pm 4.04$ & 1.943 & 0.062 \\
\hline Range & $8-24$ & & & \\
\hline
\end{tabular}

Table (2): LogMAR visual acuity pre and post-operative.

\begin{tabular}{|c|c|c|c|c|}
\hline $\begin{array}{l}\text { Log MAR } \\
\text { visual acuity }\end{array}$ & No. $=35$ & $\begin{array}{c}\text { Mean } \pm \text { SD } \\
\text { or differences }\end{array}$ & $\begin{array}{c}t- \\
\text { test }\end{array}$ & $p$ \\
\hline $\begin{array}{l}\text { Pre-operative: } \\
\text { Mean } \pm \text { SD } \\
\text { Range }\end{array}$ & $\begin{array}{l}1.25 \pm 0.49 \\
0-2\end{array}$ & - & & \\
\hline $\begin{array}{l}\text { First day: } \\
\quad \text { Mean } \pm \mathrm{SD} \\
\text { Range }\end{array}$ & $\begin{array}{l}1.26 \pm 0.35 \\
0.1-2\end{array}$ & $0.01 \pm 0.41$ & 0.164 & 0.871 \\
\hline $\begin{array}{l}\text { First week: } \\
\quad \text { Mean } \pm \text { SD } \\
\text { Range }\end{array}$ & $\begin{array}{l}1.19 \pm 0.35 \\
0.1-2\end{array}$ & $-0.07 \pm 0.44$ & -0.892 & 0.379 \\
\hline $\begin{array}{l}\text { Second week: } \\
\text { Mean } \pm \text { SD } \\
\text { Range }\end{array}$ & $\begin{array}{l}1.14 \pm 0.32 \\
0.1-2\end{array}$ & $-0.11 \pm 0.39$ & -1.712 & 0.096 \\
\hline $\begin{array}{l}\text { First month: } \\
\quad \text { Mean } \pm \text { SD } \\
\text { Range }\end{array}$ & $\begin{array}{l}0.97 \pm 0.37 \\
0-1.8\end{array}$ & $-0.27 \pm 0.38$ & -4.079 & 0.000 \\
\hline $\begin{array}{l}\text { Second month: } \\
\text { Mean } \pm \text { SD } \\
\text { Range }\end{array}$ & $\begin{array}{l}0.93 \pm 0.38 \\
0-1.8\end{array}$ & $-0.25 \pm 0.35$ & -3.889 & 0.001 \\
\hline $\begin{array}{l}\text { Six months: } \\
\quad \text { Mean } \pm \text { SD } \\
\text { Range }\end{array}$ & $\begin{array}{l}0.94 \pm 0.40 \\
0-1.8\end{array}$ & $-0.24 \pm 0.37$ & -3.534 & 0.001 \\
\hline
\end{tabular}

$p$-value $>0.05$ : Non significant (NS).

$p$-value $<0.05$ : Significant $(\mathrm{S})$.

$p$-value $<0.01$ : Highly Significant (HS)

$\bullet$ Paired $t$-test.

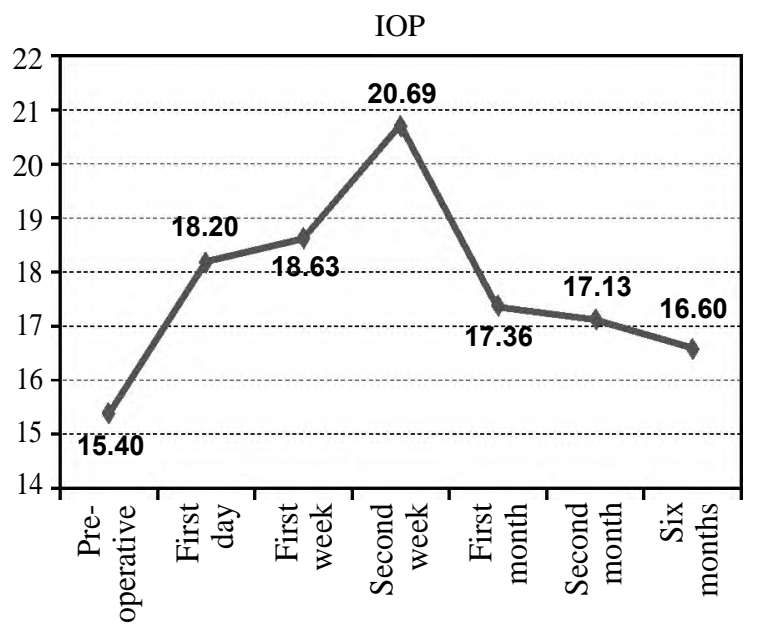

Fig. (1): IOP pre and post-operative.

The mean pre-operative vision was 1.25 with $\mathrm{SD} \pm 0.49$ (range: 0 to 2 ). The mean postoperative vision in the first day after surgery was 1.26 with $\mathrm{SD} \pm 0.35$ (range: 0.1 to 2 ). The mean post-operative vision after one week of surgery was 1.19 with SD \pm 0.35 (range: 0.1 to 2 ). The mean post-operative vision after two weeks of surgery was 1.14 with $\mathrm{SD} \pm 0.32$ (range: 0.1 to 2 ). The mean post-operative vision after one month of surgery was 0.97 with $\mathrm{SD} \pm 0.37$ (range: 0 to 1.8 ). The mean post-operative vision after two months of surgery was 0.93 with $\mathrm{SD} \pm 0.38$ (range: 0 to 1.8 ). The mean post-operative vision after six months of surgery was 0.94 with $\mathrm{SD} \pm 0.40$ (range: 0 to 1.8 ).

Table (3): Comparison between RD and PDR regarding IOP.

\begin{tabular}{|c|c|c|c|c|c|}
\hline IOP & RD & PDR & Test value• & $p$-value & Sig. \\
\hline $\begin{array}{l}\text { Pre-operative: } \\
\text { Mean } \pm \text { SD } \\
\text { Range }\end{array}$ & $\begin{array}{l}14.40 \pm 3.07 \\
9-20\end{array}$ & $\begin{array}{l}17.90 \pm 2.73 \\
13-22\end{array}$ & -3.140 & 0.004 & HS \\
\hline $\begin{array}{l}\text { First day: } \\
\quad \text { Mean } \pm \text { SD } \\
\text { Range }\end{array}$ & $\begin{array}{l}17.76 \pm 3.54 \\
10-24\end{array}$ & $\begin{array}{l}19.30 \pm 2.91 \\
15-23\end{array}$ & -1.218 & 0.232 & NS \\
\hline $\begin{array}{l}\text { First week: } \\
\quad \text { Mean } \pm \text { SD } \\
\text { Range }\end{array}$ & $\begin{array}{l}18.72 \pm 5.07 \\
9-27\end{array}$ & $\begin{array}{l}18.40 \pm 3.37 \\
14-24\end{array}$ & 0.183 & 0.856 & NS \\
\hline $\begin{array}{l}\text { Second week: } \\
\text { Mean } \pm \text { SD } \\
\text { Range }\end{array}$ & $\begin{array}{l}20.04 \pm 8.14 \\
8-40\end{array}$ & $\begin{array}{l}22.30 \pm 11.02 \\
14-49\end{array}$ & -0.670 & 0.508 & NS \\
\hline $\begin{array}{l}\text { First month: } \\
\quad \text { Mean } \pm \mathrm{SD} \\
\quad \text { Range }\end{array}$ & $\begin{array}{l}16.13 \pm 4.73 \\
8-27\end{array}$ & $\begin{array}{l}20.67 \pm 3.97 \\
17-30\end{array}$ & -2.556 & 0.016 & $\mathrm{~S}$ \\
\hline $\begin{array}{l}\text { Second month: } \\
\text { Mean } \pm \text { SD } \\
\text { Range }\end{array}$ & $\begin{array}{l}16.18 \pm 4.86 \\
10-34\end{array}$ & $\begin{array}{l}19.75 \pm 3.45 \\
17-28\end{array}$ & -1.901 & 0.068 & NS \\
\hline $\begin{array}{l}\text { Six months: } \\
\quad \text { Mean } \pm \mathrm{SD} \\
\quad \text { Range }\end{array}$ & $\begin{array}{l}15.77 \pm 3.12 \\
8-20\end{array}$ & $\begin{array}{l}18.88 \pm 2.80 \\
14-24\end{array}$ & -2.472 & 0.020 & $\mathrm{~S}$ \\
\hline
\end{tabular}

$p$-value $>0.05$ : Non significant (NS).

$p$-value $<0.05$ : Significant $(\mathrm{S})$.

$p$-value <0.01: Highly Significant (HS). $\quad \bullet$ : Independent $t$-test. 
This table showing comparison between RD and PDR patients regarding IOP. Mean IOP in PDR patients pre-operative was $17.90 \mathrm{mmHg} \pm 2.73$ while in RD patients was $14.40 \mathrm{mmHg} \pm 3.07$ ( $p$-value 0.004). Mean IOP in PDR patients first day postoperative was $19.30 \mathrm{mmHg} \pm 2.91$ while in RD patients was $17.76 \mathrm{mmHg} \pm 3.54$. Mean IOP in PDR patients one week post-operative was $18.40 \mathrm{mmHg}$ \pm 3.37 while in RD patients was $18.72 \mathrm{mmHg} \pm 5.07$. Mean IOP in PDR patients two weeks postoperative was $22.30 \mathrm{mmHg} \pm 11.02$ while in $\mathrm{RD}$ patients was $20.04 \mathrm{mmHg} \pm 8.14$. Mean IOP in PDR patients one month post-operative was $20.67 \mathrm{mmHg}$ \pm 3.97 while in $\mathrm{RD}$ patients was $16.13 \mathrm{mmHg} \pm 4.73$ ( $p$-value 0.016). Mean IOP in PDR patients two months post-operative was $19.75 \mathrm{mmHg} \pm 3.45$ while in RD patients was $16.18 \mathrm{mmHg} \pm 4.86$. Mean IOP in PDR patients six months post-operative was $18.88 \mathrm{mmHg} \pm 2.80$ while in RD patients was $15.77 \mathrm{mmHg} \pm 3.12$ ( $p$-value 0.020 ). This showing that there was clinically significant difference in IOP between two groups after one month and six months post-operative. The results showing that the early elevation of the IOP, measured two weeks after vitrectomy, is equally present in the patients with retinal detachment as well as in patients with diabetic retinopathy. However, the analysis of the two groups of patients showed higher IOP elevation in the diabetic retinopathy group.

Table (4): Comparison between pre and post-operative IOP in patients needed medical treatment.

\begin{tabular}{lcccc}
\hline & Mean & SD & $F^{*}$ & $p$-value \\
\hline Pre-operative & 15.87 & 3.18 & 5.31 & $<0.001$ \\
First day & 20.13 & 2.19 & & \\
One week & 21.06 & 4.55 & & \\
Two weeks & 25.81 & 10.87 & & \\
Four weeks & 18.87 & 5.56 & & \\
Eight weeks & 18.37 & 5.73 & & \\
Twenty four weeks & 17.00 & 3.12 & & \\
\hline
\end{tabular}

*: Repeated measure ANOVA

This table show the mean IOP with SD for 16 patients, who had increase in IOP and need medical treatment describing that after two weeks of PPV with silicone oil injection the mean IOP 25.81 with SD $10.87 \mathrm{mmHG}$ and need medical treatment with antiglaucoma drugs which continued along the period of the study (6 months).

\section{Discussion}

Silicone oil as a tamponade agent after pars plana vitrectomy in the early post-operative period may cause IOP elevation in some patients. Patients at risk of developing secondary glaucoma after silicone oil tamponade are diabetics, aphakic pa- tients and those with pre-existing glaucoma. Mechanisms responsible for developing secondary glaucoma are pupillary block due to the obstruction of peripheral iridectomy [12], emulsified silicone oil bubbles in the chamber angle [13], angle closure by anterior synechial, inflammation, rubeosis iridis, idiopathic IOP rise after silicone oil instillation as well as the surgeon's inattention and overfilling of the eye with silicone oil. The most of these cases are well controlled by topical antiglaucoma therapy, whereas the minority of patients require evacuation of the silicone oil to normalize IOP and the most refractory cases mandate penetrating filtration surgery in order to stabilize the IOP in the long term [14]

First observations of IOP elevations associated with silicone tamponade date back to the time when silicone oil was used as an instrument. In 1967, Watzke was first to record an increase in IOP upon intraocular silicone oil injection [15].

In our study 35 patients of age range from 32 to 67 years, 12 female and 23 male, there was right eye involvement in 17 cases and left eye involvement in 18 cases, 10 with PDR and 25 with RD, 23 were phakic and 12 were pseudophakic underwent pars plana vitrectomy (23 gauge) with silicone oil injection (1000cs). Intraocular pressures were measured before surgery, then at one day, one week, two weeks, 1 month, two months and six months after surgery. The mean pre-operative IOP $15.40 \pm 3.34 \mathrm{mmHg}$ (range $9.00-22.00 \mathrm{mmHg}$ ). First day post-operative mean IOP $18.20 \pm 3.40 \mathrm{mmHg}$ (range 10.00-24.00mmHg, $p<0.000$ ). One week post-operative mean IOP $18.63 \pm 4.60 \mathrm{mmHg}$ (range $9.00-27.00 \mathrm{mmHg}, p$ 0.000). Two weeks postoperative mean IOP $20.69 \pm 8.94 \mathrm{mmHg}$ (range 8 $49.00 \mathrm{mmHg}, p$ 0.001).

This showing that there is clinical significant difference in IOP pre-operative and after one day, one week, two weeks post-operative with silicone oil tamponade. One month post-operative mean IOP $17.36 \pm 4.92 \mathrm{mmHg}$ (range $8-30 \mathrm{mmHg}$ ). Two months post-operative mean IOP $17.13 \pm 4.75 \mathrm{mmHg}$ (range $10.00-34.00 \mathrm{mmHg}$ ). Six months postoperative mean IOP $16.60 \pm 3.30 \mathrm{mmHg}$ (range 8.00 to $24.00 \mathrm{mmHg}$ ). In this study the peak elevation of IOP after pars pana vitrecomy with silicone oil tamponade was two weeks after surgery mean IOP $20.69 \pm 8.94 \mathrm{mmHg}$ (range $8-49.00 \mathrm{mmHg}, p$ 0.001). An increase in IOP developed in $45.7 \%$ of the patients (16 eyes) in the post-operative period (two weeks) with mean IOP $25.81 \pm 10.87 \mathrm{mmHg}$ (range 28.00-49.00mmHg). 
Our results suggest that the early elevation of IOP is equally present in the patients with RD as well as in those with PDR. However, a qualitative analysis of the two groups of patients showed higher IOP in patients with PDR. There was nonsignificant difference in IOP between phakic and pseudophakic groups.

Silicone oil significantly affect visual acuity in both groups of patients at one month, second month and six months post-operative causing mild improvement of the visual acuity with nonsignificant difference between PDR and RD groups or phakic and pseudophakic groups.

All of these patients required medical treatment with antiglaucoma medications. No patients in this series had uncontrolled IOP.

Other results Popovic et al., [16] showed that mean values of IOP measured at one month after surgery significantly exceed the preoperative values in patients with post-vitrectomy silicone oil tamponade. Their mean IOP values measured at one month after surgery were also higher than those recorded at that same time in patients with postvitrectomy air or saline tamponade. The IOP measurements at 6 and 12 months after surgery, when silicone oil was removed from patients' eyes, showed that mean IOP values are similar in two groups of patients and do not differ much from the initial, pre-operative values.

Gonioscopy was used to assess the potential effect of silicone oil tamponade on the morphology of the anterior segment of the eye, especially the angle of the anterior chamber. In some patients, the effects of silicone oil tamponade on the anterior segment morphology were the narrowing of the angle and the development of adhesions between the iris and anterior chamber angle structures.

In another prospective study Suzana et al., [17] The results suggest that the early elevation of the IOP, measured one month after vitrectomy, is equally present in the patients with retinal detachment as well as in patients with diabetic retinopathy. However, a qualitative analysis of the two groups of patients showed higher IOP elevation in the early post-operative period in the diabetic retinopathy group. The higher IOP values in this group of patients one month after vitrectomy are to a certain extent related with the basic pathological process, diabetes, which owing to retinal ischemia causes neovascularization of the chamber angle, present in $10 \%$ of patients and it may also cause a secondary glaucoma. Although we did not found statistically significant difference in the angle width before and after vitrectomy among the observed groups, the finding of the emulsified silicone oil in $18 \%$ of patients with retinal detachment and $17 \%$ in diabetic retinopathy group may suggest its possible influence on the early elevation of the IOP values.

Other study Mohammad et al., [18] show that the mean IOP was raised in the immediate postoperative period (day 1); thereafter the levels declined after one month and six months, but remained steady at three months. Following silicone oil removal, the mean IOP showed a significant drop to normal levels in $24(80 \%)$ cases but remained at slightly raised levels in the remaining $6(20 \%)$ cases. Regression analysis showed a highly significant correlation between the pre and post silicone oil removal IOP values.

There is difference between our results and the previous results where increase of IOP started one month post-operative. This difference may be due to different methods of follow-up where in our study the follow-up was one day, one week, two weeks, one month, two months and six months post-operative, while in almost of the previous studies the follow-up starting one month postoperative.

\section{Conclusion:}

Silicone oil as a tamponade agent after pars plana vitrectomy may cause rise in the IOP values in the early post-operative period in some patients. Therefore the timely detection and appropriate ant glaucomatous treatment is extremely important since every elevation of the IOP may interfere with the positive outcome of the surgical procedure and functional visual outcome. The IOP elevation in the early post-operative course in these challenging patients presents a major risk factor for developing a secondary glaucoma.

The study showing that there is clinically significant difference in IOP pre-operative and after one day, one week, two weeks post-operative with silicone oil tamponade. Peak value of IOP was at two weeks after surgery in $53.3 \%$ of patients who need medical treatment with antiglaucoma medications. The early elevation of IOP is equally present in the patients with RD as well as in those with PDR. However, a qualitative analysis of the two groups of patients showed higher IOP in patients with PDR. Silicone oil significantly affect visual acuity in both groups of patients causing deterioration of the visual acuity with more affection in PDR group, so we recommend the early follow-up of IOP post-operative and early treatment 
of elevated IOP with topical antiglaucoma medication.

\section{References}

1- "Facts About Glaucoma". National Eye Institute. Archivedfrom the original on 28 March 2016. Retrieved 29 March 2016.

2- MANTRAVADI A.V. and VADHAR N.: "Glaucoma". Primary Care. Saunders (Elsevier), 2015.

3- MI X.S., YUAN T.F. and SO K.F.: "The current research status of normal tension glaucoma" Clinical interventions in aging, 9: 1563, 2014.

4- DUKER J.S., KAISER P.K., BINDER S., De SMET M.D., GAUDRIC A., REICHEL E., SADDA S.R., SEBAG J., SPAIDE R.F. and STALMANS P.: The International Vitreomacular Traction Study Group classification of vitreomacular adhesion, traction, and macular hole. Ophthalmology, 120 (12): 2611-9, 2013.

5- KREINER C.F.: Chemical and physical aspects of clinically applied silicones. Dev. Ophthalmol., 14: 11-9, 1987.

6- CIBIS P.A., BECKER B., OKUN E. and CANAAN S.: The use of liquid silicone in retinal detachment surgery. Arch. Ophthalmol., 68: 590-9, 1962.

7- SCOTT J.: The use of visco elastic materials in the posterior segment. Transactions of the ophthalmological societies of the United Kingdom, 103: 280-3, 1983.

8- HEIDENKUMMER H.P., MESSMER E.M. and KAMPIK A.: Recurrent vitreoretinal membranes in intravitreal silicon oil tamponade. Morphologic and Immunohistochemical Studies, 93 (2): 121-5, 1996.

9- GÜNGEL H., MENCEOGLU Y., YILDIZ B. and AKBULUT Ö.: Fourier transform infrared and $1 \mathrm{~h}$ nuclear magnetic resonance spectroscopic findings of silicone oil removed from eyes and the relationship of emulsification with retinotomy and glaucoma. Retina, 25 (3): 332-8, 2005.
10- FREEMAN H.M. and CATILLEJOS M.E.: Current management of giant retinal breaks: Results with vitrectomy and total air fluid exchange in 95 cases. Trans. Am Ophthalmol. Soc., 79: 89-102, 1981.

11- ZBOROWSKI-GUTMAN L., TRIESTER G., NAVEH N., CHEN V. and BLUMENTHAL M.: Acute glaucoma following vitrectomy and silicone oil injection. Br. J. Ophthalmol., 71: 903-6, 1987.

12- MADREPERLA S.A.: Inferior peripheral iridectomy in patients receiving silicone oil. Rates of postoperative closure and effect on oil position. Retina (Philadelphia, Pa.), 15 (2): 87-90, 1995.

13- La HEIJ E.C., HENDRIKSE F. and KESSELS A.G.: Results and complications of temporary silicone oil tamponade in patients with complicated retinal detachments. Retina, 21 (2): 107-14, 2001.

14- AL-JAZZAF A.M., NETLAND P.A. and CHARLES S. Incidence and management of elevated intraocular pressure after silicone oil injection. Journal of Glaucoma, 14 (1): 40-6, 2005.

15- WATZKE R.C.: Silicone retinopoiesis for retinal detachment. A pathologic report. Survey of Ophthalmology, 12 (4): 333, 1967.

16-POPOVIC SUIC S. and SIKIC J.: The Effect of Vitrectomy with Silicone Oil Tamponade on Intraocular Pressure and Anterior Chamber Morphology. Collegium Antropologicum., 117-25, 2001.

17- SUZANA M., SMILJKA P.S., DUBRAVKA B., MATE M., JOSIP B. and MAJA V.: Influence of Silicone Oil Tamponade after Vitrectomy on Intraocular Pressure. Collegium antropologicum., 1: 227-35, 2013.

18- MOHAMMAD J., BILAL K., MIR A.S., IFTIKHAR Q. and MOHAMMAD A.: Changes of intraocular pressure in vitrectomised eyes after removal of silicone oil. Journal of Ayub Medical College Abbottabad, 28 (2): 327-30, 2016. 


\section{تآثيرزيت السيليكون بعد إستئصال الجسم الزجاجى على ضغط العين}

الخلفية: الجلوكوما مرض معقد يؤدى فيه تلف العصب البصرى إلى فقدان بأية تدريجى لا رجعه فيه. الجلوكوما هو السبب الرئيسى الثانى للعمى

الهدف من الدراسهة: الهدف من هذه الدراسة هو تحديد التآثير المحتمل زيت السيليكن بعد إستئصال الزجاجية على الضغط داخل العين

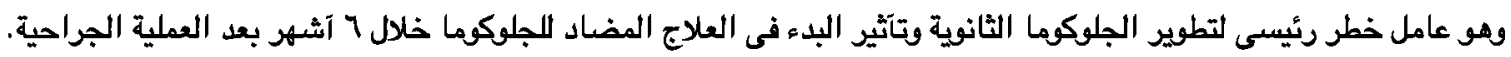

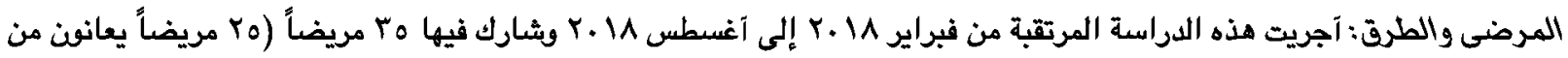

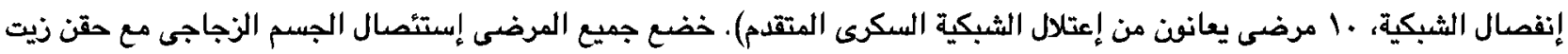

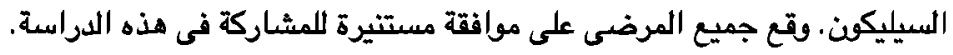

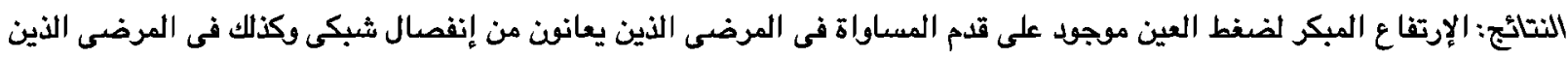

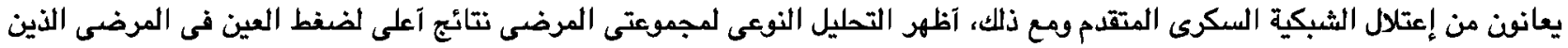

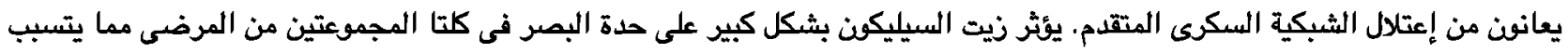
في تحسن حدة البصر في كلتا المجموعتين.

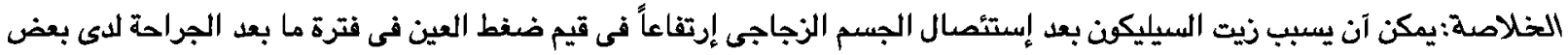

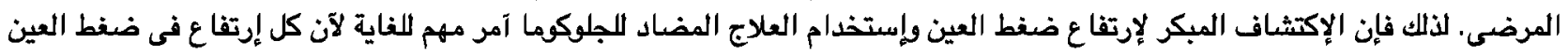

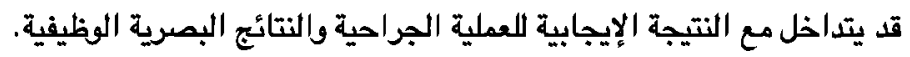

